PAPER

\title{
Post-micturitional hypotension in patients with multiple system atrophy
}

\author{
T Uchiyama, R Sakakibara, M Asahina, T Yamanishi, T Hattori
}

J Neurol Neurosurg Psychiatry 2005;76:186-190. doi: 10.1136/jnnp.2004.040972

See end of article for authors' affiliations .....................

Correspondence to: Dr Tomoyuki Uchiyama, Department of Neurology, Chiba University Graduate School of Medicine, 1-8-1 Inohana, Chuo-ku, Chiba 260-8670, Japan; uchiyama@faculty. chiba-u.jp

Received 6 March 2004 In revised form 8 May 2004

Accepted 24 May 2004
Background: Patients with multiple system atrophy (MSA) occasionally have episodes of syncope or presyncope after micturition.

Objective: To clarify the mechanism of these episodes by investigating the haemodynamic changes associated with micturition.

Methods: 25 patients with probable MSA and 16 age matched normal controls were studied. Continuous records of blood pressure and heart rate were made during water cystometry, along with the Valsalva manoeuvre, head up tilt testing, measurement of plasma noradrenaline, and calculation of coefficient of variance of RR intervals.

Results: Compared with normal controls, MSA patients had a lower baseline blood pressure, smaller blood pressure and heart rate increases during bladder filling, and an abnormal fall in blood pressure for a longer duration after voiding, resulting in significantly lower blood pressure than at baseline (mean systolic blood pressure reduction $-15.2 \mathrm{~mm} \mathrm{Hg}$ ), and hypotension compared with control blood pressure $(-29.0 \mathrm{~mm} \mathrm{Hg})$. The blood pressure fall was greater in patients with micturition syncope/pre-syncope than in those without. It was also greater in patients with abdominal straining resulting from difficulty in voiding. Other cardiovascular indices did not correlate with the fall in blood pressure.

Conclusions: Hypotension after voiding in MSA patients may result from generalised autonomic dysfunction and abnormal abdominal straining, resulting in micturition syncope. ln n patients with multiple system atrophy (MSA), episodic hypotension commonly occurs during standing, eating, and exercise, and sometimes causes dizziness (presyncope) and syncope. These conditions reflect dysfunction of the autonomic nervous system in these patients. ${ }^{1-3}$ Micturition is well known to precipitate hypotension and occasionally syncope, but the exact mechanism underlying this phenomenon is uncertain. In normal healthy subjects, however, micturition syncope is very rare and always associated with precipitating factors such as systemic vasodilatation following ethanol intake and warmth, interference with the circulation (a Valsalva manoeuvre), or a vasovagal reaction..$^{4-11}$

We have recently seen several patients with MSA complaining of dizziness (pre-syncope) and syncope in association with micturition. It seems probable that micturition syncope may occur in association with the urological and other types of widespread autonomic dysfunction in these patients. To clarify the mechanisms involved, we monitored cardiovascular and urodynamic variables during micturition in patients with MSA and in normal controls.

\section{METHODS}

Subjects

We recruited 25 patients with probable MSA. There were 13 men and 12 women, with a mean (SD) age of $61.3(6.6)$ years and a mean illness duration of 3.3 (3.2) years. Probable MSA was diagnosed by magnetic resonance imaging, pharmacological response (poorly levodopa responsive parkinsonism), and characteristic clinical manifestations such as orthostatic hypotension (fall in blood pressure of over $30 \mathrm{~mm} \mathrm{Hg}$ systolic or $15 \mathrm{~mm} \mathrm{Hg}$ diastolic), severe urinary dysfunction (urinary incontinence and voiding difficulty with large residual urine over $100 \mathrm{ml}$ because of incomplete bladder emptying), and cerebellar dysfunction, following established diagnostic criteria. ${ }^{12}$ Exclusion criteria were the presence of dementia (a score below 25/30 on the mini-mental state examination), major depression, and age over 75 years. Fourteen patients had symptoms related to postural hypotension (syncope, dizziness (pre-syncope), and so on), two had symptoms of postprandial hypotension, and four had both micturition syncope and dizziness (pre-syncope) in association with micturition. Five patients were taking sympathomimetic drugs (amezinium methylsulphate, midodrine $\mathrm{HCl}$, droxidopa) for orthostatic hypotension. Six patients were taking anticholinergic agents for micturition problems as well as drugs for constipation. No patients were continuously taking antiparkinsonian drugs or other drugs known to influence autonomic function.

We also recruited 16 age matched normal control subjects (seven men and nine women), mean age 62.3 (14.0) years. None of the control subjects had any disease, history of dizziness (pre-syncope) or syncope on any occasion, or neurological manifestations.

Neither the patients with MSA nor the control subjects had prostate hypertrophy on rectal examination and ultrasonography. All the participants gave their informed consent for the studies.

\section{General experimental protocol}

All drug treatment was withheld, beginning at least two days before the test. Studies were carried out in the morning (from 9:00) in a room with a constant ambient temperature of 20$24^{\circ} \mathrm{C}$. Subjects were encouraged to relax. After the urodynamic and cardiovascular equipment was set up and the bladder emptied, the subjects were placed in the sitting position for at least 15 minutes to achieve equilibration. We then monitored systolic, diastolic, and mean arterial blood pressure and heart rate continuously during a series of tests.

Abbreviations: MSA, multiple system atrophy; SBP, systolic blood pressure 

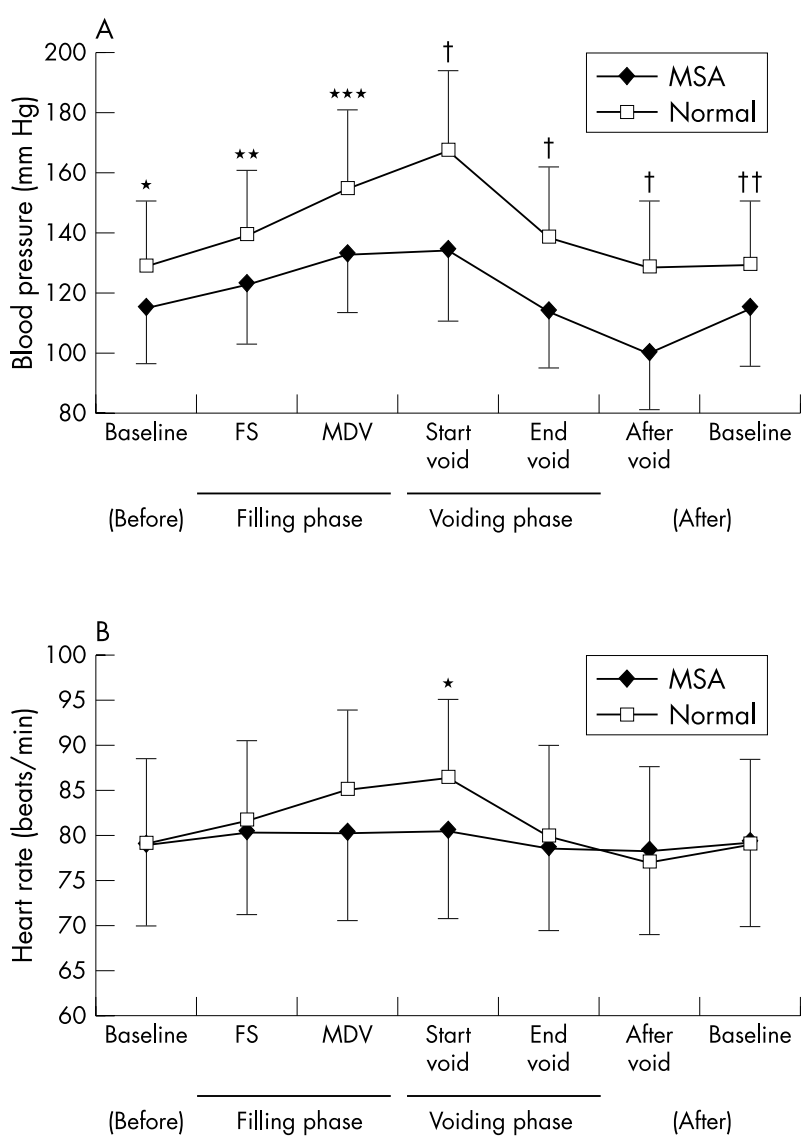

Figure 1 Systolic blood pressure and heart rate before, during, and after micturition in normal control subjects and patients with multiple system atrophy (MSA). FS, at the first sensation of wanting to void; MDV, at the maximum desire to void; Start void: at the onset of voiding; End void: at the end of voiding; After void: at the lowest value after voiding. All values for patients with MSA were significantly lower than those for normal control subjects. Values are means, error bars $=S D$. Panel $A$ : ${ }^{*} p=0.037,{ }^{* *} p=0.016,{ }^{* * *} p=0.003 v$ patients with MSA; $+p<0.001$, t†p $=0.035 v$ patients with MSA. Panel $B:{ }^{*} p=0.045 v$ patients with MSA.

\section{Blood pressure and heart rate monitoring}

During these tests, systolic blood pressure (SBP), mean blood pressure, diastolic blood pressure, and heart rate were monitored continuously using a Tonometry blood pressure monitor (Jentow, Nihon Colin, Japan), which recorded beat by beat pressure non-invasively with the subject's arm kept at heart level on a soft splint. During the head up tilt testing, Systolic, mean, and diastolic blood pressures and heart rate were measured using a sphygmomanometer and automatically recorded at one minute intervals.

\section{EMG-cystometry}

Before the first test, a transurethral and a transrectal catheter were inserted, and a sphincter EMG needle placed in the perineal area, following normal urodynamic practice. Medium fill $(50 \mathrm{ml} / \mathrm{min})$ water EMG-cystometry and uroflowmetry were carried out using an electromyography computer (Neuropack $\Sigma$, Nihon Kohden, Japan) and a urodynamic computer (Janus, Lifetech, Gaithersburg, Maryland, USA). Bladder volume at the points of the subject's first desire to void $(F S)$ and maximum desire to void $(M D V=$ bladder capacity) were recorded in the filling phase (Filling), along with abnormal detrusor contractions, including detrusor hyperreflexia. The following were recorded in the voiding phase (Void): maximum flow rate (Qmax), maximum
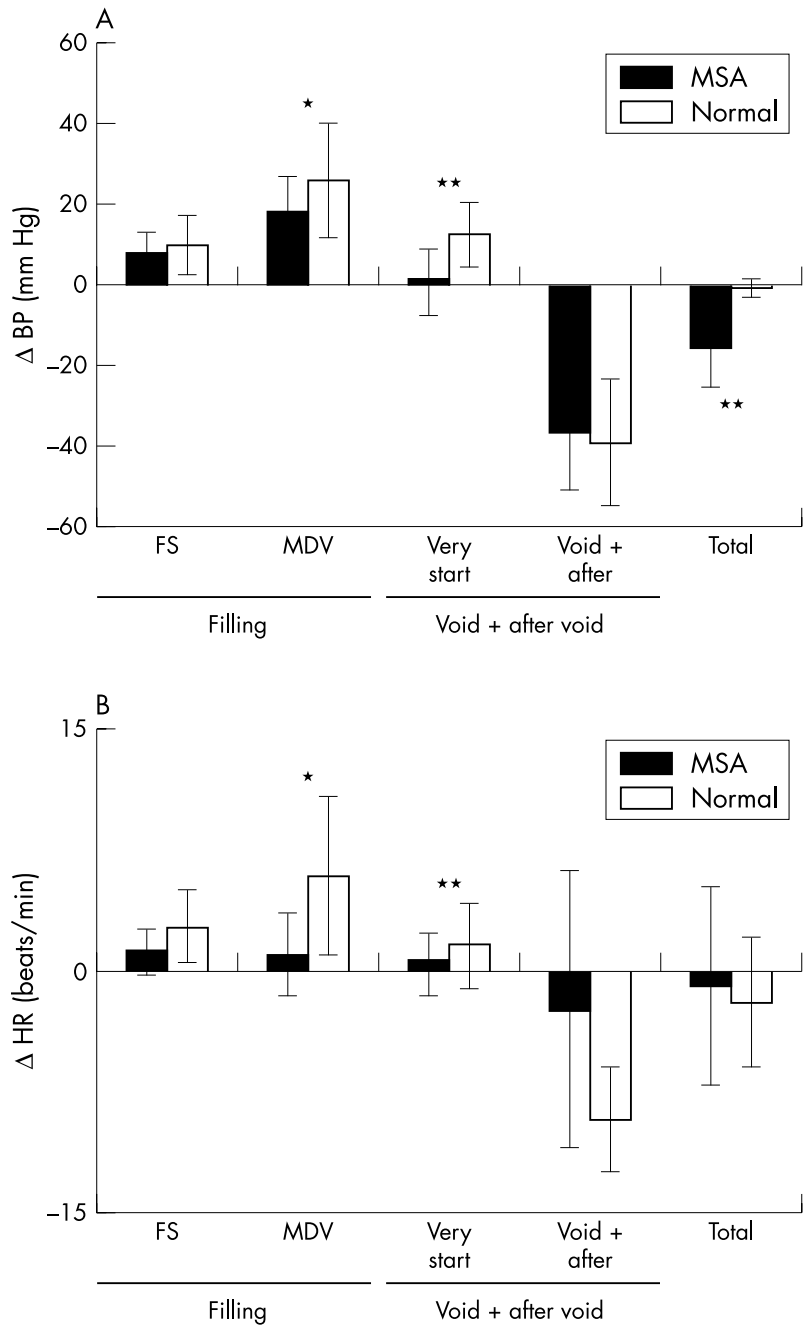

Figure 2 Changes in systolic blood pressure and heart rate at each assessment point of each phase associated with micturition in normal subjects and patients with multiple system atrophy (MSA). Filling, filling phase; FS, from baseline to first desire to void; MDV, from baseline to maximum desire to void; Void+after void, voiding phase and after voiding phase; Very start, from maximum desire to void to the onset of voiding; Void+after, from the onset of voiding to the lowest values after voiding; Total = Filling+Void+Affer void. Values are means, error bars $=$ SD. Panel A: ${ }^{*} p=0.024,{ }^{* *} p<0.001$, MSA $v$ normal controls. Panel B: ${ }^{*} p<0.001,{ }^{* *} p=0.045$, MSA $v$ normal controls.

detrusor pressure (Pdet), Pdet at Qmax, maximum abdominal pressure, maximum Watt factor (an estimate of detrusor contractility $^{13}$ ), abdominal straining pressure on performance of the Valsalva manoeuvre, and abnormal sphincter EMG, including detrusor-sphincter dyssynergy. The methods and definitions used for the urodynamic studies conformed to the standards proposed by the International Continence Society. ${ }^{14}$

\section{Valsalva manoeuvre test}

All subjects were asked to blow into a strain gauge to maintain an expiratory strain of $40 \mathrm{~mm} \mathrm{Hg}$ for 10 seconds. The SBP and heart rate responses to the Valsalva manoeuvre can be divided into four phases (I-IV). In the fourth phase, SBP change (usually an overshoot from baseline; $\mathrm{mm} \mathrm{Hg}$ ) and its duration (seconds) were assessed as markers of the sympathetic excitatory response to hypotension.

\section{Coefficient of variance of $R R$ intervals $\left(C_{R R}\right)$}

Heart beats were recorded for each subject in the sitting position with normal breathing as two series of 100 
consecutive $\mathrm{RR}$ intervals, and $\mathrm{CV}_{\mathrm{RR}}$ was calculated as the standard deviation divided by the mean $R R$ interval. $C_{R R}$ was taken from the average of two series of measurements, which were assessed as markers of parasympathetic cardiovascular tone.

\section{Head up tilt testing}

During conventional head up tilt testing, we measured systolic, mean, and diastolic blood pressure and heart rate with the subjects supine $\left(0^{\circ}\right)$, upright $\left(70^{\circ}\right)$, and supine again $\left(0^{\circ}\right)$, each for 10 minutes, on an automatic tilt table. In the upright position, maximum SBP fall was assessed as the degree of standing induced hypotension; this was considered a marker for impairment of the sympathetic excitatory response to hypotension. An SBP fall over $30 \mathrm{~mm} \mathrm{Hg}$ was considered to indicate orthostatic hypotension.

\section{Plasma noradrenaline}

Plasma noradrenaline was measured during the head up tilt test while the patients were supine $\left(0^{\circ}\right)$ and after 10 minutes in the upright position $\left(70^{\circ}\right)$. We then calculated the upright to supine ratio of plasma noradrenaline.

\section{Statistical analysis}

We compared all variables in the two subject groups using Student's $t$ test. We also compared changes within subject groups by the paired $t$ test or analysis of variance (ANOVA). We tested the correlations among all of the variables using Pearson's correlation coefficient. We considered the differences statistically significant at probability ( $p$ ) values of $<0.05$. Unless otherwise indicated, values are means (SD).

\section{RESULTS}

\section{Changes in SBP and heart rate during micturition in controls}

The SBP and heart rate responses in the normal controls are shown in figs 1 and 2 and are summarised in table l. Resting SBP was 129.0 (21.4) $\mathrm{mm} \mathrm{Hg}$ and resting heart rate was 79.2 (9.4) beats/min.

During bladder filling (from baseline to maximum desire to void (Filling), both SBP and heart rate increased significantly by 26.0 (14.0) $\mathrm{mm} \mathrm{Hg}$ (range 9 to 70) for SBP, and by 5.9 (4.8) beats/min (range 0 to 17) for heart rate, respectively.

At the onset of voiding, transient significant increases in SBP and heart rate of 12.4 (7.7) $\mathrm{mm} \mathrm{Hg}$ (range 1 to 27) and 1.5 (2.6) beats/min (range 0 to 12 ) were recorded.

During voiding (from the start to the end of voiding (Void), SBP and heart rate decreased by 29.4 (14.3) $\mathrm{mm} \mathrm{Hg}$ (range -65 to -9 ) and by 6.6 (5.9) beats/min (range -16 to 4 ), respectively.
Changes in SBP and heart rate from baseline levels to the end of voiding (Filling+Void) were -8.9 (5.9) $\mathrm{mm} \mathrm{Hg}$ (range 0 to 20 ) and -0.7 (2.8) beats/min (range -5 to 5 ).

After voiding (from the end of voiding to the lowest value (After void), SBP and heart rate decreased by 9.5 (7.0) $\mathrm{mm} \mathrm{Hg}$ (range -24 to 0 ) and by 2.6 (3.1) beats/min (range -16 to 1 ), respectively; the lowest levels of SBP and heart rate were recorded 48.8 (54.6) seconds after the end of voiding.

Changes in SBP and heart rate from the start of voiding to the lowest values after voiding (Void+After void) were -39.0 (15.5) $\mathrm{mm} \mathrm{Hg}$ (range -81 to -16 ) and -9.2 (3.2) beats/min (range -18 to 1 ).

Overall, changes in SBP and heart rate from baseline levels to the lowest value after voiding (Filling + Void + After void) were -0.6 (1.8) $\mathrm{mm} \mathrm{Hg}$ (range -5 to 2 ) and -1.9 (4.0) beats $/ \mathrm{min}$ (range -10 to 4 ) (both NS). These slight changes returned to the baseline level immediately after the end of voiding (Recovery). Mean and diastolic blood pressure responses showed the same pattern.

None of the changes in SBP associated with micturition correlated with any urodynamic variables, such as bladder volume, detrusor pressure, or abdominal pressure.

\section{Changes in SBP and heart rate during micturition in MSA patients}

The SBP and heart rate responses in the patients with MSA are shown in figs 1 and 2 and are summarised in table 1 . Resting SBP was 115.2 (19.3) $\mathrm{mm} \mathrm{Hg}$ and resting heart rate was 79.4 (9.3) beats/min; SBP was significantly lower than in the controls $(-13.8 \mathrm{~mm} \mathrm{Hg}, \mathrm{p}=0.037)$.

During Filling, significant increases in SBP and heart rate of 17.5 (9.1) $\mathrm{mm} \mathrm{Hg}$ ( 1 to 39) and 1.0 (2.5) beats/min ( -3 to 4) were recorded, but these increases were lower than in the controls $(p=0.024$ and $p<0.001$, respectively).

At the onset of voiding, transient increase in SBP and heart rate of $0.8(8.0) \mathrm{mm} \mathrm{Hg}$ ( -16 to 21 ) and 0.4 (1.9) beats/min $(-4.3$ to 5$)$ were recorded. These increases were significantly smaller than those in the controls $(\mathrm{p}<0.001$ and $\mathrm{p}=0.045$, respectively).

During Void, SBP and heart rate decreased by -22.6 (14.7) $\mathrm{mm} \mathrm{Hg}$ (range -65 to -2 ) and -2.1 (4.7) beats/min (range -20 to 4); these decreases were similar to those in the controls.

Changes in SBP and heart rate during Filling+Void were -1.6 (13.2) $\mathrm{mm} \mathrm{Hg}$ (range -35 to 14 ) and -0.7 (4.7) beats/ min (range -20 to 5); the change in SBP was less than in the controls $(\mathrm{p}=0.002)$.

During After void, SBP and heart rate decreased by 13.7 (9.1) $\mathrm{mm} \mathrm{Hg}$ (range -30 to 0 ) and by 0.2 (4.7) beats $/ \mathrm{min}$ (range -35 to 6); the blood pressure decrease was larger and

Table 1 SBP and heart rate before, during, and after micturition in normal control subjects and patients with multiple system atrophy

\begin{tabular}{|c|c|c|c|c|c|c|c|c|c|c|}
\hline & & \multirow{2}{*}{$\begin{array}{l}\text { Baseline } \\
\text { (resting) }\end{array}$} & \multicolumn{2}{|l|}{ Filling } & \multicolumn{3}{|l|}{ Voiding } & \multirow[b]{2}{*}{ Total change } & \multirow[b]{2}{*}{ Lowest level } & \multirow[b]{2}{*}{ Time } \\
\hline & & & FS & MDV & Very start & Void & After void & & & \\
\hline $\begin{array}{l}\text { SBP } \\
(\mathrm{mm} \mathrm{Hg})\end{array}$ & $\begin{array}{l}\text { Normal } \\
\text { MSA }\end{array}$ & $\begin{array}{l}129.0(21.4) \\
115.2(19.3)^{*}\end{array}$ & $\begin{array}{l}+10.1(7.3) \\
+7.2(5.6)\end{array}$ & $\begin{array}{l}+26.0(14.0) \\
+17.5(9.1)^{* *}\end{array}$ & $\begin{array}{l}+12.4(7.7) \\
+0.8(8.0)^{\star * *}\end{array}$ & $\begin{array}{l}-29.4(14.3) \\
-22.6(14.7)\end{array}$ & $\begin{array}{l}-9.5(7.0) \\
-13.7(9.1)\end{array}$ & $\begin{array}{l}-0.6(1.8) \\
-15.2(9.8)^{\star * *}\end{array}$ & $\begin{array}{l}128.4(22.4) \\
100.0(19.0)^{* * *}\end{array}$ & $\begin{array}{l}48.8(54.6)(\mathrm{s}) \\
93.1(90.4)+(\mathrm{s})\end{array}$ \\
\hline $\begin{array}{l}\text { HR } \\
\text { (beats/ } \\
\text { min) }\end{array}$ & $\begin{array}{l}\text { Normal } \\
\text { MSA }\end{array}$ & $\begin{array}{l}79.2(9.4) \\
79.4(9.3)\end{array}$ & $\begin{array}{l}+2.7(2.2) \\
+1.1(1.4)\end{array}$ & $\begin{array}{l}+5.9(4.8) \\
+1.0(2.5) \dagger \dagger\end{array}$ & $\begin{array}{l}+1.5(2.6) \\
+0.4(1.9) \dagger+\dagger\end{array}$ & $\begin{array}{l}-6.6(5.9) \\
-2.1(4.7)\end{array}$ & $\begin{array}{l}-2.6(3.1) \\
-0.2(4.7)\end{array}$ & $\begin{array}{l}-1.9(4.0) \\
-0.9(6.1)\end{array}$ & $\begin{array}{l}77.2(10.5) \\
78.5(9.3)\end{array}$ & \\
\hline
\end{tabular}

Values are mean (SD).

${ }^{*} \mathrm{p}=0.037,{ }^{* *} \mathrm{p}=0.024,{ }^{* * *} \mathrm{p}<0.001 v$ normal controls; $\mathrm{tp}=0.001,+\uparrow \mathrm{p}<0.001,+\dagger+\mathrm{p}=0.045 v$ normal controls.

Baseline, values during resting phase; Filling, filling phase; FS, changes from baseline to first desire to void, MDV, the changes from baseline to maximum desire to void; Voiding, voiding phase; Very start, the changes from maximum desire to void to the onset of voiding; Void, the changes from the onset of voiding to the end of voiding; After void, the changes from the end of voiding to the lowest values after voiding; Total change, the changes during Filling+Void+After void; Lowest value, the lowest values after voiding; Time, the time from the end of voiding to the lowest values after voiding.

$H R$, heart rate; SBP, systolic blood pressure. 
the heart rate decrease smaller than in the controls, but the differences were not significant. However, the lowest levels of SBP and heart rate were recorded 93.1 (90.4) seconds (0 to $335)$ after the end of voiding, significantly more delayed than in the controls $(\mathrm{p}=0.001)$.

Changes in SBP and heart rate during Void + After void were -36.4 (14.0) $\mathrm{mm} \mathrm{Hg}(-65$ to -15$)$ and -2.4 (8.5) beats $/ \mathrm{min}$ ( -30 to 13$)$; this blood pressure decrease was nearly equal to the changes in the controls, but the heart rate decrease was smaller than in the controls (NS).

Overall, the change in SBP during Filling + Void + After void was $-15.2(9.8) \mathrm{mm} \mathrm{Hg}(-45$ to 0$)$, and which was less than in the controls; the change in heart rate during Filling+Void + After void was -0.9 (6.1) beats/min $(-20$ to 5$)$, which was the same as in the controls.

These changes returned to the baseline level (Recovery) 69.8 (71.6) seconds (2 to 250) after the nadir of SBP and heart rate; this was significantly longer than in the controls $(\mathrm{p}<0.001$ for both). Mean and diastolic blood pressure responses showed a similar pattern.

Nineteen of our patients with MSA (76\%), including 71\% of those without micturition syncope or pre-syncope, had an SBP change that was greater than the mean +3SD of the value for the normal subjects during Filling+Void + After void (more than $-7 \mathrm{~mm} \mathrm{Hg}$ ). Ten of our patients with MSA (40\%) had an SBP change of more than $20 \mathrm{~mm} \mathrm{Hg}$ during Filling+Void+After void. Three of our MSA patients (12\%) had an SBP change of more than $30 \mathrm{~mm} \mathrm{Hg}$ during Filling+Void+After void.

In some cases, SBP decreased during voiding in a phasic manner, in parallel with high phasic abdominal straining $(-25.0$ to $-33.0 \mathrm{~mm} \mathrm{Hg})$. The change in SBP during Void + After void showed a positive correlation with maximum abdominal pressure during voiding $(\mathrm{p}=0.019, r=0.465)$

SBP change during Filling+Void+After void was greater in MSA patients with a history of micturition syncope or presyncope $(-24.5 \mathrm{~mm} \mathrm{Hg})$ than in those without such a history $(-14.1 \mathrm{~mm} \mathrm{Hg})(\mathrm{p}=0.046)$.

\section{The other cardiovascular indices}

Compared with the controls, the patients with MSA had a lower overshoot response change and a longer overshoot duration time on the Valsalva manoeuvre, at 9.3 (15.8) v 39.2 (19.9) $\mathrm{mm} \mathrm{Hg}$, and 14.4 (13.6) v 4.4 (1.4) s ( $<<0.001$ and $\mathrm{p}=0.008$, respectively). The patients with MSA had a lower $\mathrm{CV}_{\mathrm{RR}}$ than the controls, at $1.5(0.5) v 2.9(0.9)(\mathrm{p}<0.001)$. The changes in blood pressure in the head up tilt test were -27.5 (21.1) $\mathrm{mm} \mathrm{Hg}$ systolic and -25.5 (16.4) $\mathrm{mm} \mathrm{Hg}$ diastolic. The average supine noradrenaline concentration was 219.8 (117.2) $\mathrm{pg} / \mathrm{ml}$. The upright to supine noradrenaline ratio was $1.7(0.4)$. The changes in SBP associated with micturition were not correlated with any of these variables.

\section{DISCUSSION}

\section{During filling}

In this study, the normal control subjects showed a gradual increase in systolic blood pressure and a slight increase in heart rate during bladder filling, presumably indicating an increase in cardiovascular sympathetic activity associated with the filling phase. In previous studies on normal subjects drinking large amounts of water or undergoing transurethral water infusion, a marked increase in systolic blood pressure (of 4 to $52 \mathrm{~mm} \mathrm{Hg}$, mean values 15 to $27 \mathrm{~mm} \mathrm{Hg}$ ) accompanied the maximum desire to void. ${ }^{15-17}$ Previous studies on normal subjects have also shown that bladder filling is accompanied by generalised sympathetic activity-for example, increased sympathetic activity in the peroneal nerve ${ }^{16}$ and increased vasoconstriction in the skin. ${ }^{18}$ In animal experiments, inputs from bladder mechanoreceptors during filling are transmitted to the lumbar sympathetic neurones by the sacral dorsal roots. ${ }^{19}$ Bladder distension in animals also increases peripheral and central sympathetic nerve activities, ${ }^{20-25}$ thus increasing SBP and heart rate. Our results reflect these previous findings.

In the present study, the patients with MSA showed slight increases in blood pressure during bladder filling (mean 17.5 $\mathrm{mm} \mathrm{Hg}$ ), and their heart rate did not change. The changes in both blood pressure and heart rate during bladder filling were significantly smaller than in the controls $(p=0.024$ and $\mathrm{p}<0.001)$. A previous report on patients with MSA showed that blood pressure did not change during bladder filling (mean $-2 \mathrm{~mm} \mathrm{Hg}$ ). ${ }^{17}$ In addition, in the present study the patients with MSA had impairment of their sympathetic excitatory responses to a fall in blood pressure-for example, impaired response to head up tilt, a decreased upright to supine noradrenaline ratio, and a decreased overshoot response on the Valsalva manoeuvre. The patients with MSA also had impairment of the cardiovascular parasympathetic system (for example, a low $C_{R R}$ ). Some of these findings have been described in other reports. ${ }^{125}$ They suggest that patients with MSA may have impaired cardiovascular sympathetic excitatory responses to bladder filling rather than an unusual cardiovascular parasympathetic excitation, resulting in only slight blood pressure and heart rate changes during filling. Thus the patients with MSA may be less prone to autonomic dysreflexia associated with bladder filling than patients with high spinal cord lesions, in whom this is a common phenomenon. ${ }^{26}{ }^{27}$ We have not in fact experienced autonomic dysreflexia in patients with MSA.

\section{During and after voiding}

In this study, normal control subjects showed a transient increase in blood pressure and heart rate at the onset of voiding, which was not associated with abdominal straining. This response may reflect a transient increase in sympathetic activity. This transient increase in blood pressure and heart rate was significantly smaller in the patients with MSA.

Normal control subjects had a decrease in blood pressure and heart rate during voiding. Previous reports showed that cardiovascular sympathetic activity in the bladder filling phase disappeared in the voiding phase, and that blood pressure and heart rate returned to baseline after voiding in normal subjects. ${ }^{15-25}$ Furthermore, in the voiding phase of experimental animals, the bladder parasympathetic nerve supply is excited, while the urethral sympathetic nerve supply is inhibited. These changes return to normal immediately after voiding. ${ }^{19}$ The findings suggest that during voiding, cardiovascular autonomic activity-for example, the decrease in systolic blood pressure and heart rate-may well correlate with urinary autonomic activity, in which the sympathetic supply is inhibited and parasympathetic supply excited.

After voiding in the normal controls, changes in blood pressure and heart rate from baseline to their lowest values were minimal $(-0.6 \mathrm{~mm} \mathrm{Hg}$ and -1.9 beats/min, respectively), as in previous reports. ${ }^{5-11}$ Patients with MSA also showed a similar decrease in blood pressure during voiding, in spite of a small increase in systolic blood pressure during bladder filling, which resulted in hypotension (that is, the change in systolic blood pressure from baseline to its lowest value was significant). In addition, this hypotensive period was much longer than in the controls $(p<0.001$ and $p<0.001$, respectively). During these periods, heart rate change was smaller than in the controls, though the difference was not significant. This pattern of blood pressure and heart rate change after the end of voiding is different from neurally mediated syncope, ${ }^{28} 29$ and the blood pressure falls associated with voiding were not correlated with the falls occurring on head up tilt. These findings suggest that an abnormal 
dominant parasympathetic state may occur transiently after voiding. However, the mechanism of this is unclear and further evaluation is needed.

In patients with MSA, the decrease in systolic blood pressure during and after voiding had a positive correlation with maximum straining during voiding $(\mathrm{p}=0.019$, $r=-0.465$ ). In some of our patients with MSA, blood pressure during voiding showed a pronounced phasic decrease in parallel with abdominal straining. This occurred in two of four symptomatic patients with MSA. Straining during voiding reflects the voiding difficulty that occurs in this disorder. ${ }^{130}$ Abdominal straining (the Valsalva manoeuvre) increases intrathoracic pressure and impairs venous return; this is known to cause prolonged hypotension in patients with MSA.

The blood pressure fall from baseline after voiding was greater in MSA patients with a history of micturition syncope or pre-syncope (mean $-24.5 \mathrm{~mm} \mathrm{Hg}$ ) than in those without such a history $(-14.1 \mathrm{~mm} \mathrm{Hg})(\mathrm{p}=0.046)$. Furthermore, in the patients with MSA, baseline systolic blood pressure was significantly lower than in the controls (mean -13.8 $\mathrm{mm} \mathrm{Hg}$ ), which also contributes to post-micturitional hypotension.

\section{Conclusions}

In the normal control subjects, blood pressure and heart rate increased in parallel with bladder filling, but the values returned to baseline after voiding; normal individuals rarely have micturition syncope unless there are special unusual circumstances. Patients with MSA, on the other hand, had a lower baseline systolic blood pressure, a smaller increase in systolic blood pressure and heart rate during bladder filling, an almost equal blood pressure decrease during and after voiding, and a significantly prolonged period of low blood pressure after voiding, resulting in abnormal hypotension. Because of this, micturition syncope tends to occur in patients with MSA. These findings most probably reflect generalised autonomic dysfunction (possibly an abnormal dominant parasympathetic state) and abnormal abdominal straining because of coexisting voiding difficulties.

\section{Authors' affiliations}

T Uchiyama, R Sakakibara, M Asahina, T Hattori, Department of Neurology, Chiba University Graduate School of Medicine, Chiba, Japan

T Yamanishi, Department of Urology, Dokkyo University School of Medicine, Dokkyo, Japan

Competing interests: none declared

\section{REFERENCES}

1 Cohen J, Low P, Fealey R, et al. Somatic and autonomic function in progressive autonomic failure and multiple system atrophy. Ann Neurol 1987;22:692-9.
2 Mathias CJ, Holly E, Armstrong E, et al. The influence of food on postural hypotension in three groups with chronic autonomic failure: clinical and therapeutic implications. J Neurol Neurosurg Psychiatry 1991;54:726-30.

3 Smith GDP, Mathias CJ. Postural hypotension enhanced by exercise in patients with chronic autonomic failure. Q J Med 1995;88:251-6.

4 Gastaut H. Le syncope nocturne des hypervagotoniques, sa différentiation dávec l'épilepsie morphéique. Rev Neurol (Paris) 1957;57:420-1.

5 Proudfit WL, Forteza ME. Micturition syncope. N Engl J Med 1959;260:328-31.

6 Lyle CB, Monroe JT, Flinn DE, et al. Micturition syncope: Report of 24 cases. N Engl J Med 1961;265:982-6.

7 Coggin CH, Lillington GA, Gray CP. Micturition syncope. Arch Intern Med 1964;113:14-18.

8 Lukash WM, Sawyer G, Davis J. Micturition syncope produced by orthostasis and bladder distension. N Engl J Med 1964;270:341-4.

9 Donker DNJ, Robles de Medina EO, Kieft J. Micturition syncope. Electroencephalogr Clin Neurophysiol 1972;33:551-2.

10 Schoenberg BS, Kuglitsh JF, Karnes WE. Micturition syncope - not a single entity. JAMA 1974;229:1631-3.

11 Sakakibara R, Hattori T, Kita K, et al. Urodynamic and cardiovascular measurements in patients with micturition syncope. Clin Auton Res 1997; 7:219-21.

12 Gilman S, Low PA, Quinn N, et al. Consensus statement on the diagnosis of multiple system atrophy. J Auton Nerv Syst 1998:74:189-92.

13 Griffiths DJ. Assessment of detrusor contraction strength or contractility. Neurourol Urodyn 1991;10:1-18.

14 Abrams P, Blaivas JG, Stanton SL, et al. The standardization of terminology of lower urinary tract function. Produced by the International Continence Society Committee on Standardization of Terminology. Scand J Urol Nephrol 1988; 114(suppl):5-19.

15 Szasz JJG, Whyte HM. Effect of distension of the bladder and of contraction of sphincters on blood pressure. BMJ 1967;2:208-10.

16 Fagius J, Karhuvaara S. Sympathetic activity and blood pressure increases with bladder distension in humans. Hypertension 1989;14:51 1-17.

17 Petersen T, Mathias CJ, Alam M, et al. Simultaneous arterial and urinary bladder pressure recordings in multiple system atrophy and in spinal disorders with detrusor hyperreflexia. Clin Auton Res 1997;7:299-304.

18 Adams-Ray J, Norlen G. Bladder distension reflex with vasoconstriction in cutaneous venous capillaries. Acta Physiol Scand 1950;23:95-109.

19 de Groat WC, Steers WD. Autonomic regulation of the urinary bladder and sexual organs. In: Loewy AD, Spyer KM, eds. Central regulation of autonomic functions. New York: Oxford University Press, 1990:310-33.

20 Watkins AL. Reflex responses of the nictitating membrane and the blood pressure to distension of the bladder and rectum. Am J Physiol 1939; 121:32-9.

21 Taylor DEM. Afferent pathways and efferent mechanisms in the bladder viscero-vascular reflex. Q J Exp Physiol 1968;53:262-72.

22 Weaver LC. Organization of sympathetic responses to distension of urinary bladder. Am J Physiol 1985;248:R236-40.

23 Schondorf R, Laskey W, Polosa C. Upper thoracic sympathetic neuron responses to input from urinary bladder afferents. Am J Physiol 1983;245:R311-20.

24 Elam M, Thoren P, Snensson TH. Locus coeruleus neurons and sympathetic nerves: activation by visceral afferents. Brain Res 1986;375:117-25.

25 Dotson R, Ochoa J, Marchettini P, et al. Sympathetic neural outflow directly recorded in patients with primary autonomic failure: clinical observations, microneurography, and histopathology. Neurology 1990:40:1079-85.

26 Guttmann L, Whitteridge D. Effects of bladder distension on autonomic mechanisms after spinal cord injury. Brain 1947;70:361-404.

27 Mathias CJ, Christensen NJ, Corbette JL, et al. Plasma catecholamines during paroxysmal neurogenic hypertension in quadriplegic man. Circ Res 1976;39:204-8.

28 Grubb BP, Olshansky B, eds. Syncope: mechanism and management. New York: Futura Publishing Co, 1998.

29 Grabb BP, Karas B. Neurally mediated syncope. In: Mathias CJ, Bannister R, eds. Autonomic failure: a textbook of clinical disorders of the autonomic nervous system, 4th ed. New York: Oxford University Press, 1999:437-47.

30 Sakakibara R, Hattori T, Uchiyama T, et al. Videourodynamic and sphincter motor unit potential analyses in Parkinson's disease and multiple system atrophy. J Neurol Neurosurg Psychiatry 2001;71:600-6. 